\title{
Radiocesium concentrations and DNA strand breakage in two species of amphibians from the Chornobyl exclusion zone
}

\author{
C.H. Jagoe, A.J. Majeske, T.K. Oleksyk, T.C. Glenn and M.H. Smith \\ University of Georgia, Savannah River Ecology Laboratory, \\ P.O. Drawer E, Aiken, SC 29802, U.S.A.
}

\begin{abstract}
Relatively few studies have considered impacts of the 1986 nuclear accident at Chornobyl on lower vertebrate populations. Amphibians are recognized as sensitive indicators of environmental degradation and pollution, and some amphibian population declines may be associated with contaminant-induced stress. Amphibians also utilize both aquatic and terrestrial habitats, which facilitates comparison of radionuclide accumulation and effects in different environments. We sampled sympatric frog species from a highly contaminated area within the Chornobyl exclusion zone and from a nearby, less contaminated area in August - September 1999. Radiocesium was measured in whole frogs and in muscle samples. Whole body mean radiocesium for Rana esculenta from Gluboke Lake, a highly contaminated area, was $22.3 \mathrm{~Bq} / \mathrm{g}$ wet mass; $R$. terrestris from the same area contained $53.4 \mathrm{~Bq} / \mathrm{g}$ wet mass. Radiocesium levels in frogs from Emerald Camp, a less contaminated area, were about an order of magnitude lower. In both locations, whole body radiocesium concentrations were higher in $R$ terrestris than in $R$. esculenta, probably reflecting dietary differences between species. Mean muscle radiocesium concentrations were generally lower than whole body concentrations, and muscle and whole body concentrations were highly correlated within individuals. We used pulsed field-gel electrophoresis to examine the size distribution of DNA fragments in muscle tissue from a subsample of $R$. terrestris from both locations. Increased proportions of smaller DNA fragments, suggesting DNA strand breakage, occurred in $R$. terrestris from the more contaminated location. Results support the concept that amphibians are useful in assessing radionuclide accumulation and effects in contaminated areas. However, differences among species must be considered in evaluating contaminant concentrations and potential effects.
\end{abstract}

\section{INTRODUCTION}

Relatively few studies have considered the impacts of the nuclear accident at Chornobyl Nuclear Power Plant (ChNPP) in April 1986 on lower vertebrates. The contaminated region around the ChNPP, the Exclusion Zone, is closed to agriculture and most other human activities, and represents a natural refuge inhabited by diverse and apparently abundant wildlife. Amphibians are sensitive indicators of environmental degradation and pollution [1] that utilize both aquatic and terrestrial ecosystems. Amphibians are represented in this zone by two species of salamanders and nine species of frogs and toads [2]. The frogs Rana terrestris and $R$ esculenta are locally abundant in the highly contaminated marshes inside of the Exclusion Zone. These amphibians could serve as useful biomonitors in contaminated areas because they integrate aquatic and terrestrial environments and can be obtained in large quantities for population studies.

Frequency distributions of radionuclides in animals are seldom normal and frequently skewed [3]. Knowledge of frequency distributions of radionuclide concentrations within populations is useful for a variety of reasons. For example, trophic transfer may be directly influenced by the distribution of contaminants among food items [4] because the probability of encountering a highly contaminated prey item is related to the frequency distribution, particularly the distribution's mean, variance, kurtosis and skewness. Contaminant distributions may also allow inference about the biological processes influencing contaminant uptake and transfer. A study of the distributions of ${ }^{137} \mathrm{Cs}$ among functionally different but closely related organisms may provide information about factors influencing contaminant uptake and accumulation.

When amphibians are present in contaminated areas, they can serve as model species for studies of genetic responses to radiation exposure. Female frogs lay hundreds of eggs per clutch, making them an ideal group for studying germline mutations in vertebrate species [cf. 5]. Exposure to ionizing radiation can produce a number of genetic alterations, including breakage of DNA strands. Such lesions, or their inaccurate repair, can result in higher level effects such as carcinogenesis or heritable mutations. A number of techniques have been proposed to detect DNA strand breakage [6,7], but detecting DNA strand breaks at environmentally-realistic levels of radiation exposure has proven difficult. This may be because chronic irradiation does not break DNA into small fragments that are readily detectable, but instead yields larger fragments that are more difficult to separate with 
conventional techniques. A promising new technique is pulsed-field gel electrophoresis (PFGE) $[6,8,9]$. In this technique, orthogonally-oriented, pulsed electric fields are used to separate relatively large pieces of DNA that are not resolvable by conventional electrophoresis.

We sampled $R$. terrestris and $R$ esculenta from a highly contaminated area within the Chomobyl exclusion zone, and from a reference area with lower levels of contamination, and measured whole-body and muscle radiocesium concentrations. Although both species are common within the exclusion zone, $R$ terrestris is the more easily identified of the two species. Moreover, $R$. esculenta is part of a multiple species complex exhibiting genome parasitism [10], which could make it difficult to interpret genetic alterations in response to contaminant exposure. Therefore, we used a subsample of $R$. terrestris to test whether there was evidence for increased DNA strand breakage in animals from one area with high levels of radiocesium contamination and another area with lower levels of contamination.

\section{MATERIALS AND METHODS}

\subsection{Study Area}

The primary study area for this investigation was the Exclusion Zone around Chornobyl, Ukraine. This zone is approximately $120 \mathrm{~km}$ north of Kyiv (we use current Ukrainian spelling). There have been a number of studies in this area since the accident in April 1986, and many indicate that, ecological processes have altered the distribution of radionuclides in the years since the accident [11-14]. However, amounts of longer-lived radioisotopes such as ${ }^{137} \mathrm{Cs}$ and ${ }^{90} \mathrm{Sr}$ around Chornobyl are still substantial, and environmental radioactivity exceeds background levels by several orders of magnitude [12].

Amphibians were collected in a three week period in August-September 1999 from two sites within the

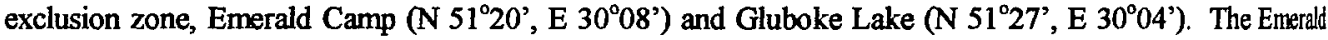
Camp is located on the shore of the reservoir that served as a source of cooling water for the failed Chomobyl reactor. This location had mature deciduous forest with heavy underbrush and some standing water. Previous surveys indicated that this area had lower levels of contamination than areas to the north of the failed reactor, such as Gluboke Lake [11]. Gluboke Lake is part of the old bed of the Prypiat River that had been cut off from the main channel before the accident. A radioactive cloud from the reactor accident in April 1986 touched the sufface of Gluboke Lake, depositing a substantial amount of radioactivity.

A total of 82 individuals were collected at the two locations. At Gluboke Lake we obtained $14 R$ terrestris, $15 R$. esculenta, and at Emerald Camp $20 R$. terrestris, and $33 R$ esculenta. Animals were frozen in liquid $\mathrm{N}_{2}$ and transported to the U.S. for analysis.

\subsection{Sample Collection and Analysis for ${ }^{137} \mathrm{Cs}$}

Radiocesium was measured using a Minaxiy-5000 (Packard Instruments) automatic gamma counter with a 7.6x $7.6 \mathrm{~cm}$ NaI detector. Data from low-activity standards with the same geometry as the samples were used to calculate detector efficiency. Counting times were adjusted to produce $\sigma<5 \%$, and background count rates were determined every eight samples. Detection limits were calculated according to [15]. Values below mirimum detection levels were included in subsequent data analysis as negative numbers, since omitting these values would bias the analyses [16]. Radiocesium was first measured in individual whole frogs. Then, muscle was sampled from the rear legs and measured. All analyses were completed during a two-month period, within four monthsof collection; given the long half- life of radiocesium, it was not necessary to correct for decay during this period when comparing concentrations among muscle and whole body or among species. Tissues were weighed, driedat $50^{\circ} \mathrm{C}$ and reweighed to determine water content; radiocesium concentrations are expressed on a wet-weight basis.

\subsection{Pulse-field electrophoresis}

Twenty-five individuals were used for DNA analysis by PFGE. Six to eight replicate samples were run per individual. Leg muscle tissue was macerated with plastic pestles in $1.7 \mathrm{~mL}$ centrifuge tubes, and the resulting washed whole cells were imbedded in agarose prior to proteinase K digestion of proteins $(17,18)$. Agarose plugs with frog DNA were run in $1.0 \%$ agarose gels in a BioRad CHEF DRIII for 22 hours at 4.5 volts $/ \mathrm{cm}$ and switch times of 40-120 seconds. Yeast chromosomal DNA (BioRad) and HiLo (Minnesota Molecular) were used as standards on the outside and middle lanes of each gel. Following electrophoresis, gels were stained with Sybr Gold (Molecular Probes), and images captured using an Eagle Eye II (Strategene) video capture system To 
assure comparability among gels, magnification and placement for imaging were kept constant, and multiple images per gel were collected with varying aperture and exposure times to maximize sensitivity for each sample.

\subsection{Statistical analysis}

Statistical analyses were performed using SAS v.8.1 software (SAS Inc, Cary NC). Radiocesium concentrations were analyzed using nonparametric methods (Kruskal-Wallis tests, Spearman's rank correlation). For DNA strand breakage analysis, digitally-recorded images of gels with fluorescence intensity values (0-255) for individual pixels were used. Fluorescence intensity was directly proportional to DNA concentration, so the intensity values provide a quantitative measure of the relative amount of DNA at a particular location on each gel. A block of pixels representing the origin of each lane of a gel (that is, the well where the DNA sample was applied to the gel) was defined as region 1. Six additional blocks of pixels of equal size were assigned at regular intervals corresponding to known molecular size markers along each lane; these were designated as regions 2-7. We compared relative fluorescence intensities by region to test whether there were different amounts of various size fragments of DNA among individuals and locations. Data were arcsin transformed to meet assumptions of analysis of variance and analyzed by ANOVA; parallel analyses using nonparametric methods (Kruskal-Wallis tests) yielded identical conclusions.

\section{RESULTS}

\subsection{Whole body and muscle ${ }^{137} \mathrm{Cs}$ concentrations}

Whole-body radiocesium concentrations for $R$. esculenta from Gluboke Lake averaged $22.3 \mathrm{~Bq} / \mathrm{g}$ wet mass; $R$ terrestris from the same area averaged $53.4 \mathrm{~Bq} / \mathrm{g}$ wet weight (Figure 1). Whole body radiocesium was higher in $R$ terrestris than in $R$. esculenta both at Emerald Camp (by Kruskal-Wallis test, $X^{2}=11.4, p=0.003$,), and Gluboke Lake $\left(X^{2}=7.0, p=0.030\right)$. Muscle radiocesium concentrations at Gluboke Lake averaged 15.0 and 15.7 $\mathrm{B} q \mathrm{~g}$ wet weight in $R$ esculenta and $R$. terrestris, respectively (Figure 2). At Emerald Camp, muscle radiocesium averaged 1.50 in $R$ esculenta and 3.52 in $R$. terrestris. There was no significant difference in muscle radiocesium between species at either location $(p \geq 0.05)$. Within species, both whole body and muscle radiocesium concentrations were higher at Globoke Lake than at Emerald Camp $\left(X^{2}=30.1, p<0.001\right.$ and $X^{2}=19.4 p<0.001$ for $R$ esculenta; $X^{2}=17.6, p<0.001$ and $X^{2}=9.83, p=0.009$ for $R$. terrestris, respectively)

At the Emerald Camp location, whole body radiocesium was correlated with muscle radiocesium in $R$. terrestris $\left(r_{s}=0.69, p \leq 0.001\right)$ and $R$ esculenta $\left(r_{s}=0.65, p<0.001\right)$ (Fig. 2a). At Gluboke Lake, whole body tadiocesium correlated with muscle radiocesium in $R$. esculenta $\left(r_{s}=0.48, p<0.05\right)$ but not in $R$. terrestris . Overall, whole body radiocesium correlated with muscle radiocesium in $R$ terrestris $\left(r_{s}=0.70, p<0.001\right)$ and $R$ esculenta $\left(r_{s}=0.78, p<0.001\right)$. $R$. terrestris also had larger variance then $R$. esculenta both at Emerald Camp $\left(F_{32,19}, \mathrm{p} \leq 0.0001\right)$ and Gluboke Lake $\left(F_{14,13}, \mathrm{p} \leq 0.045\right)$.
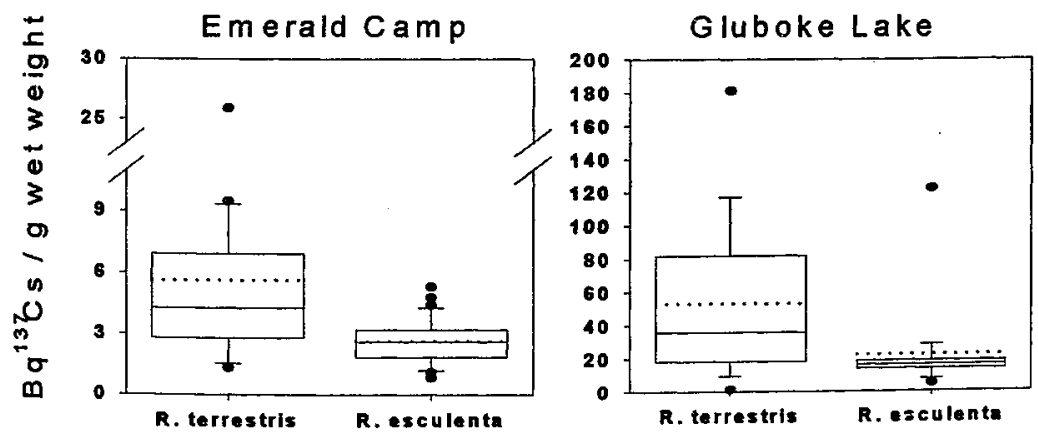

Figure 1. Whole body radiocesium in two species of Rana from two locations near Chornobyl. Data are presented as box plots, where the solid lines of the box indicate the $25^{\text {th }}, 50^{\text {th }}$ (median) and $75^{\text {th }}$ percentiles, respectively. Staples indicate the $10^{\text {th }}$ and $90^{\text {th }}$ percentiles, and values outside this range are presented as dots. Means are indicated by dotted lines. 

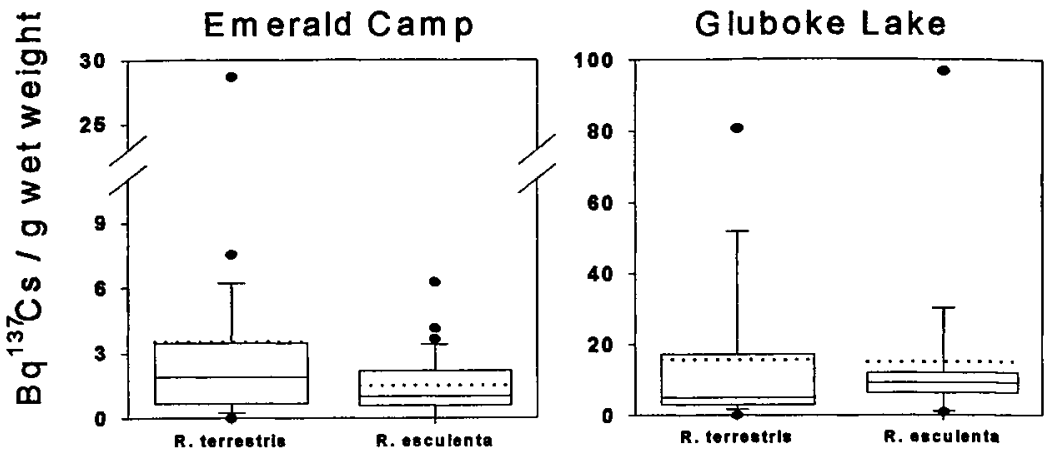

Figure 2. . Muscle radiocesium in two species of Rana from two locations near Chornobyl. Data are presented as box plots, where the solid lines of the box indicate the $25^{\text {th }}, 50^{\text {th }}$ (median) and $75^{\text {th }}$ percentiles, respectively. Staples indicate the $10^{\text {th }}$ and $90^{\text {th }}$ percentiles, and values outside this range are presented as dots. Means are indicated by dotted lines.

\subsection{Analysis of DNA strand-breaks with pulse-field electrophoresis}

Regardless of location, about $33 \%$ of $R$ terrestris DNA remained in the well where it was applied to the gel (Region 1, see Figure 3). Moving away from the origin, there was significantly greater fluorescence in regions 2 and 3 in $R$ terrestris from Emerald Camp than in those from Gluboke Lake (F=5.56,p<0.05 and F=6.40,p< 0.05 , respectively; Figure 3). There were no differences in fluorescence values between locations for regions 4 and 5 . In the most distant regions (6 and 7), fluorescence values were significantly greater in $R$ terrestris from Gluboke Lake $(F=17.37, p<0.001$ and $F=131.1, p<0.001$, respectively; Figure 3$)$. The differences are consistent with a greater fraction of smaller DNA fragments in $R$ terrestris from Gluboke Lake.

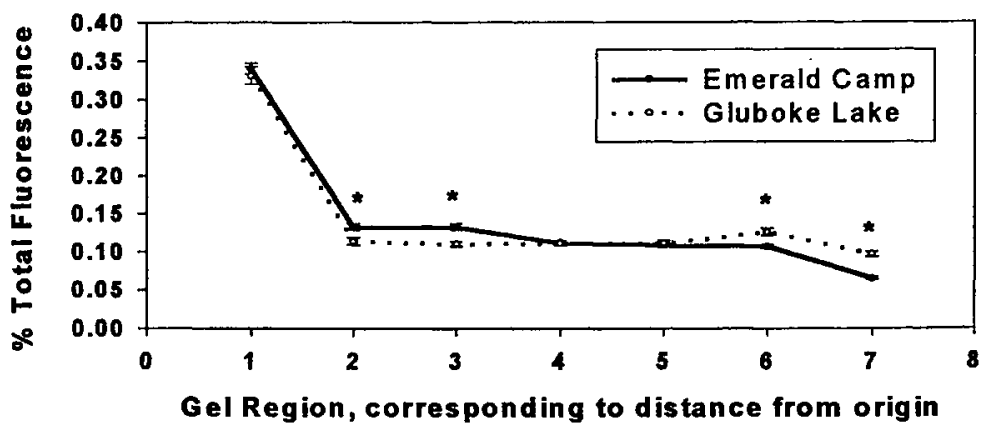

Figure 3. Percent of total fluorescence, corresponding to DNA content, in various gel regions for $R$. terrestris from two locations near Chornobyl. Asterisks indicate significant differences $(p<0.05)$ in fiuorescence between locations at particular regions.

\section{DISCUSSION}

As expected, radiocesium concentrations were greatest in frogs from Gluboke Lake, because areas to the north of the ChNPP received much more contamination due to prevailing winds during the accident [14]. The consistent differences in body radiocesium between species at both locations probably reflect interspecific differences in habitat use and diet. $R$ terrestris uses more terrestrial habitats than $R$ esculenta, which favors littoral habitats. Radiocesium concentrations were extremely high in muscle from small mammals utilizing terrestrial habitats in this area [11], whereas concentrations in muscle of fishes from this area were substantially lower [13]. Radiocesium mobility and bioavailability is greater in dry, sandy soils than in wet, organic-rich sediments [12], consistent with higher radiocesium concentrations in amphibians that make greater use of terrestrial environments.

Radiocesium concentrations were greater in whole frogs than in frog muscle. This seems counterintuitive, because radiocesium is an analog of $\mathrm{K}$, and most $\mathrm{K}$ in animals is intracellular. Most wet tissue by weight in amphibians is muscle, and most radiocesium should be within muscle tissue. Whole body concentrations should therefore be lower than muscle concentrations, because tissues such as bone that add to whole body mass are 
relatively low in radiocesium The probable explanation is that these frogs have recently fed on highly contaminated items, and that the higher whole body concentrations are associated with radiocesium in the digestive system. The more terrestrial species, $R$. terrestris, shows a greater difference between whole body and muscle radiocesium than the more aquatic $R$. esculenta. This is the pattem that would be expected if $R$. terrestris is feeding on more contaminated prey from terrestrial habitats. In both species, body and muscle radiocesium were significantly correlated, suggesting differences in dietary intake are reflected in differences in muscle burden.

Box plots of contaminant distribution in these amphibians (Figures 1 and 2) suggest that the distributions are skewed and non-normal. The locations and species with the highest mean radiocesium values also had the highest variances; this correlation is characteristic of lognormal distributions, but not normal ones. Earlier studies $[3,4]$ also reported non-normal radiocesium distributions in biota. Frequency distributions of contaminants can reflect multiple interrelated factors including spatial heterogeneity and scale, individual movement, home range, body size, and diet. Variances of the radiocesium concentrations were higher in the more terrestrial species $(R$. terrestris) than in littoral $R$. esculenta. This is consistent with the observation that small terrestrial vertebrates (eg. mammals) often have more skewed radiocesium distributions than aquatic vertebrates (e.g. fish) [3].

The distribution of DNA as measured by PFGE clearly shows a shift from longer to shorter DNA fragments in frogs exposed to higher levels of contaminants. This clear difference is somewhat surprising considering the relatively small sample sizes, low doses of ionizing radiation relative to most PFGE studies, and the high repair rate of most DNA double strand breaks. It is important to note, that this preliminary study of frogs lacks replication at the population level. Thus, although it is interesting to note the correlation between shorter fragment lengths and increased concentrations of radiocesium, a causal relationship can not be inferred from these data alone and additional studies of are warranted. However, our data support the hypothesis of increased DNA strand-breakage within individuals receiving higher doses of radiation in Exclusion Zone. Our data also illustrate the utility of amphibian species both in monitoring radiocesium contamination in wetland environments, and as models of the effects of chronic radionuclide exposure.

\section{Acknowledgements}

Support for this research came from a contract (DE-FC09-96SR18546) between the U. S. Department of Energy and The University of Georgia. Facilities and logistical support in Ukraine were provided through M. Bondarkov, Director of the International Radioecology Laboratory, Slavutych, Ukraine. Other help came from L. Dueck, A. Arkhipov, I. Chizhevskyj, P. E. Johns, and I. Shchohalevich.

\section{References}

[1] Carey C., Nicolas C., Rollins-Smith L., Develop. Comp. Immunol. 23 (1999) 459-472.

[2] Gaschak, S.P. Zlissky, A.A., Buntova, O.P. Verterbrate Fauna of Chornobyl Zone. Report of the Ministry of Emergencies and Population Protection from the Consequences of the Chornobyl Disaster, Slavutich-Chornobyl, Ukraine. (2000) 82pp.

[3] Oleksyk T.K., Gaschak S.P., Glenn T.C., Jagoe C.H., Peles J.D., Purdue J.R., Tsyusko O.V., Zalissky

0.0 ., Smith M.H., J. Environ. Radioactivity In press. (2001).

[4] Pinder J.E., III, Smith M.H., in Mineral Cycling in Southeastern Ecosystems. F. G. Howell,

J.B.Gentry. and M. H. Smith (Eds.), Energy Research and Development Agency Symposium Series,

(CONF-740513, US Energy Research and Development Administration 1975), pp. 107-121.

[5] Ellegren H., Lindgren G., Primmer C.R, Moller A.P., Nature 389 (1997) 593-596.

[6] Whitaker S.J., Powell S.N., McMillan T.J., Eur. J. Cancer 27 (1991) 922-928

17] Shugart L.R., Ecotoxicology 9 (2000) 329-340.

[8] Sutherland J.C., Monteleone D.C., Trunk J.G., Bennett P.V., Sutherland B.M. Electrophoresis 22 (2001) 843-854.

[9] Sutherland BM, Bennett PV, Sutherland JC. Analytical Biochemistry 239 (1996) 53-60.

[10] Semlitsch R.D, Reyer H.U., Evolution 46 (1992) 665-676.

[1] Chesser R.K, Sugg D.W., Lomakin M.D., Van Den Bussche R.A., DeWoody J.A., Jagoe C.H., Dallas C.E., Whicker F.W., Smith M.H., Gashchak S.P., Chizhevsky I.V., Lyabik V.V., Buntova E.G., Holloman K, Baker R, Environ. Toxicol. Chem. 19 (1999) 305-312.

[12] Ivanov Y.A., Lewyckyj N., Levchuk S.E., Prister B.S., Firsakova S.K, Arkhipov N.P., Arkhipov A.N., Kruglov S.V., Alexakhin R.M., Sandalls J., Askbrant S., Journal of Environmental Radioactivity 
35 (1997) 1-21.

[13] Jagoe C.H., Dallas C.E., Chesser R.K, Smith M.H., Lingenfelser S.K, Lingenfelser J.T., Holloman K, Lomakin M.D., Ecotoxicology 7 (1998) 201-209.

[14] Medvedev Z.A., Trends in Ecology and Evolution 9 (1994) 369-371.

[15] Currie L.E., Analytical Chemistry 40 (1968) 586-593.

[16] Newman M.C., Dixon P.M., Looney B.B., Pinder J.E., Water Resources Bulletin 25 (1989) 905-916,

[17] Birren B., Lai, E. Pulsed Field Gel Electrophoresis, A Practical Guide. Academic Press, New York (1993)

[18] Biorad Laboratories CHEF-DRIII Pulsed Field Electrophoresis Systems Instruction Manual and Applications Guide. Biorad Laboratories, Hercules CA (1997). 